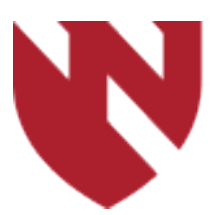

September 2020

\title{
Methotrexate Is Associated With Reduced Cardiovascular Risk in U.S. Veterans With Rheumatoid Arthritis Independent of Disease Activity Modification
}

\author{
Tate Johnson \\ University of Nebraska Medical Center \\ Joshua Baker \\ University of Pennsylvania \\ Punyasha Roul \\ University of Nebraska Medical Center \\ Harlan Sayles \\ University of Nebraska Medical Center \\ Grant W. Cannon \\ University of Utah
}

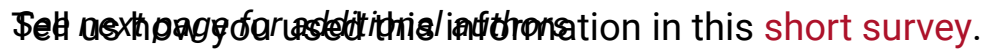

Follow this and additional works at: https://digitalcommons.unmc.edu/gmerj

Part of the Higher Education Commons, and the Medicine and Health Sciences Commons

\section{Recommended Citation}

Johnson, T., Baker, J., Roul, P., Sayles, H., Cannon, G. W., Sauer, B., Mikuls, T., , England, B. Methotrexate Is Associated With Reduced Cardiovascular Risk in U.S. Veterans With Rheumatoid Arthritis Independent of Disease Activity Modification. Graduate Medical Education Research Journal. 2020 Sep 29; 2(1).

https://digitalcommons.unmc.edu/gmerj/vol2/iss1/19

This Conference Proceeding is brought to you for free and open access by DigitalCommons@UNMC. It has been accepted for inclusion in Graduate Medical Education Research Journal by an authorized editor of DigitalCommons@UNMC.For more information, please contact digitalcommons@unmc.edu. 


\section{Methotrexate Is Associated With Reduced Cardiovascular Risk in U.S. Veterans With Rheumatoid Arthritis Independent of Disease Activity Modification}

\section{Creative Commons License}

\section{(c) (1) (9)}

This work is licensed under a Creative Commons Attribution-Noncommercial-No Derivative Works 4.0 License.

\section{Authors}

Tate Johnson, Joshua Baker, Punyasha Roul, Harlan Sayles, Grant W. Cannon, Brian Sauer, Ted Mikuls, and Bryant England 


\section{Methotrexate Is Associated With Reduced Cardiovascular Risk in U.S. Veterans With Rheumatoid Arthritis Independent of Disease Activity Modification}

Tate Johnson', Joshua Baker ${ }^{2}$, Punyasha Roul', Harlan Sayles', Grant W. Cannon³, Brian Sauer ${ }^{3}$, Ted Mikuls ${ }^{1}$, Bryant England ${ }^{1}$

${ }^{1}$ University of Nebraska Medical Center, Department of Internal Medicine, Division of Rheumatology

2University of Pennsylvania, Department of Internal Medicine, Division of Rheumatology

${ }^{3}$ University of Utah, Department of Internal Medicine, Division of Rheumatology

Mentor: Bryant R. England

Program: Internal Medicine, Division of Rheumatology

Type: Original Research

Background: Rheumatoid arthritis (RA) patients are at increased risk of cardiovascular disease (CVD). Methotrexate, a mainstay in RA treatment, appears to mitigate this risk, though the mechanism of this benefit is unclear.

Methods: We observed a cohort of Veterans with RA for incident CVD from 4/2005 to $4 / 2015$. A composite of acute myocardial infarction (AMI), coronary revascularization, stroke, and heart failure hospitalization
(CHF) was identified using administrative data and validated by medical record review. Baseline and time-varying covariates were assessed using registry and administrative data. Methotrexate exposure was defined by linkage with pharmacy dispensing data. Marginal structural models, incorporating time-varying confounders into the propensity to receive methotrexate, were used to assess the association of methotrexate with CVD. To examine whether association of methotrexate with CVD was mediated through disease activity modification, we used sequential Cox models including post-methotrexate disease activity.

Results: Over 9,490 person-years of follow up, incidence of composite CVD events $(n=357)$ was lower in methotrexate-exposed patients (incidence rate ratio 0.82 ). In marginal structural models, methotrexate was associated with reduced risk of composite CVD (hazard ratio [HR] 0.72) and CHF (HR 0.40). In sequential Cox models, adjustment for post-methotrexate disease activity did not alter its association with CVD events (range $\Delta$ HR -0.03 to 0.01 ).

Conclusion: Methotrexate was associated with reduced composite CVD and CHF, independent of disease activity. Modification of RA disease activity was not a primary driver of lower CVD risk, suggesting a directly beneficial effect of methotrexate that should be considered when modifying treatment regimens in RA patients.

https://doi.org/10.32873/unmc.dc.gmerj.2.1.018

\section{Factors Affecting Emergency Medicine Residency Applicant Perceptions of Competitiveness and Number of Applications Submitted}

Erin Karl'1, Zach Jarou ${ }^{2}$, Chichen Qiu ${ }^{3}$, Aaron Barksdale ${ }^{1}$

${ }^{1}$ University of Nebraska Medical Center, Department of Emergency Medicine

${ }^{2}$ University of Chicago, Section of Emergency Medicine, Chicago, IL

${ }^{3}$ Stanford University, Department of Emergency Medicine, Stanford, CA

\section{Mentor: Aaron Barksdale}

Program: Emergency Medicine

Type: Original Research

Background: Applicants to emergency medicine (EM) residency applied to an average of 56.6 programs each in 2018 , more than double the number compared to one decade ago.

Methods: Fourth-year medical students $(n=132)$ attending the Emergency Medicine Residents' Association Medical Student Forum at the 2018 Scientific Assembly were asked to complete a 24 question survey. Response rate was $80.2 \%$. Students who were IMGs, couples or military matching, had not taken Step 1, or had not completed or received their grade from at least one EM rotation were excluded (leaving $\mathrm{n}=72$ ). Descriptive and summary statistics were used.

Results: The median Step 1 score was 226.3 , and $15.9 \%$ were AOA. Students were $61.1 \% \mathrm{MD}$ and $38.9 \%$ DO. Step 1 scores decreased perceptions of competitiveness for $53 \%$, while increasing perception in $35 \%$. Feedback from EM mentors and rotations ( $75 \%$ and $71 \%$ ), leadership and extracurricular activities (67\% and 66\%), and Standardized Letter of Evaluation (SLOE) strength $(65 \%)$ contributed to increased perception of competitiveness (Figure 1). The most common factors increasing applications submitted included; EM is becoming more competitive ( $83 \%)$, lack of SLOE transparency $(70 \%)$, belief they are less competitive than the average applicant $(69 \%)$, or unsure about their competitiveness $(66 \%)$.

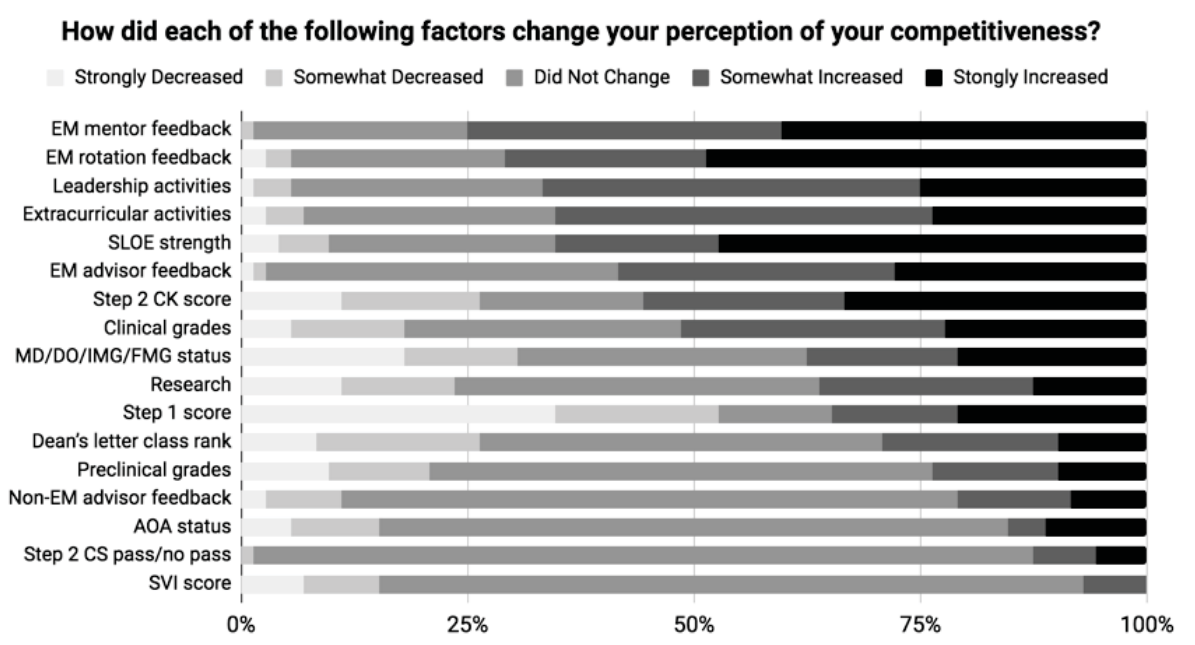

Figure 1. Factors that changed applicants' self-perception of competitiveness. $(n=72)$

\begin{abstract}
Conclusions: Step 1 scores caused more than half of applicants to decrease their perception of competitiveness. Feedback from EM mentors and EM rotations increased applicants' perception of competitiveness. The top three factors increasing residency applications were the belief that EM is becoming more competitive, lack of SLOE transparency, and an applicant's belief that they are less competitive.

https://doi.org/10.32873/unmc.dc.gmerj.2.1.019
\end{abstract}

